\title{
Fabrication and in vitro Evaluation of Allopurinol Fast Dissolving Tablets Using Croscarmellose Sodium, Sodium Starch Glycolate and Crospovidone as Superdisintegrants
}

\section{Md. Mizanur Rahman Moghal ${ }^{1}$, Sujit Chandra Mazumder ${ }^{2}$, Dilshad Noor Lira ${ }^{3}$ and Abu Shara Shamsur Rouf ${ }^{3}$}

\author{
${ }^{1}$ Department of Pharmacy, Mawlana Bhashani Science and Technology University, Santosh, Tangail-1902, \\ Bangladesh \\ ${ }^{2}$ Department of Pharmacy, Noakhali Science and Technology University, Noakhali-3814, Bangladesh \\ ${ }^{3}$ Department of Pharmaceutical Technology, University of Dhaka, Dhaka-1000, Bangladesh
}

Received: November 30, 2015; Accepted: June 12, 2016; Published (web): June 20, 2016

\begin{abstract}
The main objective of the study was to formulate fast dissolving tablets of allopurinol to achieve better dissolution rate and further improving the bioavailability to provide a quick onset of action. Nine formulations of fast dissolving tablets of allopurinol were prepared by direct compression technique using croscarmellose sodium (Group A), sodium starch glycolate (Group B) and crospovidone (Group C) as superdisintegrants in different concentrations. All formulations showed satisfactory mechanical strength, uniform weight $\&$ drug content, and lesser wetting time \& dispersion time. In vitro disintegration time, dispersion time, wetting time of all nine formulations were obtained from $11.67 \pm 0.88$ to $40.67 \pm 1.20$ seconds, $32.67 \pm 0.88$ to $65.33 \pm 1.45$ seconds and $21.67 \pm 0.33$ to $50.00 \pm 1.53$ seconds respectively. Amongst all formulations, formulation F-9 prepared by $4.17 \%$ crospovidone showed least disintegrating time of $11.67 \pm 0.88$ seconds along with rapid drug release ( $98.88 \%$ within 15 minutes).
\end{abstract}

Key words: Fast dissolving tablets, Allopurinol, Superdisintegrants, Disintegration time.

\section{INTRODUCTION}

Oral route represents the most preferred way of administration of most therapeutic agents used to produce systemic effects, owing to its numerous advantages and high patient compliance when compared to many other routes. ${ }^{1}$ However, many patient groups such as the elderly, children, and patients who are mentally retarded, non-cooperative, nauseated, or on reduced liquid intake/diets have difficulties in swallowing tablet and hard gelatin capsule dosage forms. To overcome these limitations, pharmaceutical scientists have developed innovative drug delivery systems known as Fast Dissolving/ Disintegrating Tablets (FDTs) which disintegrate rapidly in saliva, usually in a matter of seconds,

Correspondence to: Abu Shara Shamsur Rouf Phone: +88029661900-73; Cell: 01916670403;

Email: rouf321@yahoo.com without the need of water or chewing. ${ }^{2}$ The medication can then be absorbed partially or entirely into the systemic circulation from vascular smooth muscle cells than on cardiac muscle blood vessels in the sublingual mucosa, or it can be swallowed as a solution to be absorbed from the gastrointestinal tract. $^{3-5}$

Gout is a metabolic disorder which is characterized by hyperuricemia and resultant deposition of monosodium urate in the tissues, particularly the joints and kidneys. ${ }^{6,7}$ Allopurinol, the first strong anti-gout agent, is known as 1,5-dihydro4H-pyrazolo[3,4-d]pyrimidin-4-one. It is rapidly absorbed from upper GIT after oral administration with a bioavailability varying from $67 \%$ to $90 \%$ and volume of distribution of about $1.6 \mathrm{~L} / \mathrm{kg}$. Plasma half-life is about $2 \mathrm{hr}$ for allopurinol and 18-30 hr for 
oxypurinol (the active metabolite of allopurinol) after an oral dose.

In this study, an attempt has been made to fabricate fast dissolving tablet formulations of allopurinol by direct compression method using croscarmellose sodium, sodium starch glycolate and crospovidone as superdisintegrants. This research was also focused to evaluate the in vitro release characteristics, dissolution kinetics and release mechanism of the formulated tablets as well as to evaluate the influence of superdisintegrants level on the release rate.

\section{MATERIALS AND METHODS}

Drugs and chemicals. Allopurinol powder, microcrystalline cellulose PH102, lactose, saccharin sodium, talc and magnesium stearate were kindly provided by Incepta Pharmaceuticals Limited (Savar, Dhaka, Bangladesh) as gift samples. Croscarmellose sodium, sodium starch glycolate and crospovidone were obtained from Globe Pharmaceuticals Limited (Begumgonj, Noakhali, Bangladesh).Hydrochloric acid (Merck, Germany, 0.01N) was used as dissolution medium. All solvents and chemicals used were of analytical grade.

Preparation of allopurinol FDTs. The critical parameters to formulate a FDT are the selection of superdisintegrant and optimization of its concentration. Superdisintigrants like croscarmellose sodium, sodium starchglycolate and crospovidone were used in different ratios $(2.5,3.33$ and $4.16 \%$, respectively). Tablets each containing $100 \mathrm{mg}$ of allopurinol were prepared as per composition given in Table 1.

Evaluation of powder blends. The powder blend was evaluated for flow properties as follows and presented in Table 2.

Bulk density. ${ }^{8,9}$ Apparent bulk density $(\rho b)$ was determined by pouring the blend into a graduated cylinder. The bulk volume $\left(\mathrm{V}_{\mathrm{b}}\right)$ and weight of the powder $(\mathrm{W})$ was determined. The bulk density $(\rho b)$ was calculated using the formula: $\mathbf{\rho b}=\mathbf{W} / \mathbf{V}_{\mathbf{b}}$

Tapped density. ${ }^{10}$ A measuring cylinder containing a known mass of blend (W) was tapped for a fixed time (100 tapping). The minimum volume $\left(\mathrm{V}_{\mathrm{t}}\right)$ occupied in the cylinder and weight of the blend (W) was measured. The tapped density ( $\rho t)$ was calculated using the following formula: $\rho \mathbf{t}=\mathrm{W} / \mathbf{V}_{\mathbf{t}}$

Compressibility index. ${ }^{11}$ The simplest method of measurement of free flow of powder is compressibility, given by compressibility index (I), which is calculated as follows: $\mathbf{C I}=\{(\boldsymbol{\rho} \mathbf{t}-\boldsymbol{\rho b}) /$ pt $) \times 100$

Hausner's ratio. ${ }^{12}$ This is an indirect index of ease of powder flow. It is calculated by the following formula: Hausner's Ratio $=\boldsymbol{\rho t} / \mathbf{\rho b}$

Angle of repose. $^{13}$ Angle of repose was determined using funnel method. The blend was poured through a funnel that can be raised vertically until a maximum cone height (h) was obtained. Radius of the heap (r) was measured and the angle of repose $(\theta)$ was calculated using the following formula: $\theta=\tan ^{-1}(\mathbf{h} / \mathbf{r})$

Evaluation of tablets. The tablets were evaluated for the following parameters:

Thickness and diameter test. ${ }^{9}$ Five tablets were taken and their thickness and diameter was measured using Varnier callipers. Five trials for each formulation were made and are expressed in $\mathrm{mm}$ (table3).

Weight variation. ${ }^{14}$ Ten tablets from each formulation were randomly selected and average weight was determined (Table3).

$\%$ weight variation $=\{$ (Average weight - Individual weight) / Average weight $\} \times 100$

Friability test. ${ }^{14}$ Three tablets were initially weighed and placed to a friabilator, operated at 25 rpm for $4 \mathrm{~min}$ or run upto100 revolutions and dropping the tablets at a height of 6 inches in each revolution. Tablets were de-dusted using a soft muslin cloth, re-weighedand the loss in weight (friability) was determined as follows:

$$
\begin{aligned}
& \% \text { Friability }=\{(\text { initial weight }- \text { final } \\
& \text { weight }) /(\text { initial weight })\} \times 100
\end{aligned}
$$

Hardness test. ${ }^{15}$ Three tablets were randomly picked and hardness of tablets was determined by 
using a hand operated hardness test apparatus (Electrolab EH-01P). It is expressed in Kgf (Table 3).

In vitro disintegration time. ${ }^{16}$ The disintegration time for all formulations was determined by using disintegration test apparatus containing $900 \mathrm{ml}$ of $0.01 \mathrm{~N} \mathrm{HCl}$ solution (Table 3 ).
In vitro dispersion time. ${ }^{17}$ One tablet was placed in a beaker containing $10 \mathrm{ml}$ of $0.01 \mathrm{~N} \mathrm{HCl}$ solution at $37 \pm 0.5^{\circ} \mathrm{C}$ and the time in seconds required to complete dispersion was determined. Three trials for each formulation were performed (Table3).

Table 1. Proposed formulations for allopurinol fast dissolving tablets.

\begin{tabular}{lccccccccc}
\hline \multicolumn{1}{c}{ Ingredients (mg) } & \multicolumn{3}{c}{ Group A } & \multicolumn{3}{c}{ Group B } & \multicolumn{3}{c}{ Group C } \\
\cline { 2 - 10 } & F1 & F2 & F3 & F4 & F5 & F6 & F7 & F8 & F9 \\
\hline Allopurinol & 100 & 100 & 100 & 100 & 100 & 100 & 100 & 100 & 100 \\
Croscarmellose sodium & 6 & 8 & 10 & - & - & - & - & - & - \\
Sodium starch glycolate & - & - & - & 6 & 8 & 10 & - & - & - \\
Crospovidone & - & - & - & - & - & - & 6 & 8 & 10 \\
Microcrystalline cellulose PH102 & 60 & 60 & 60 & 60 & 60 & 60 & 60 & 60 & 60 \\
Lactose & 64 & 62 & 60 & 64 & 62 & 60 & 64 & 62 & 60 \\
Saccharin Sodium & 4 & 4 & 4 & 4 & 4 & 4 & 4 & 4 & 4 \\
Talc & 2 & 2 & 2 & 2 & 2 & 2 & 2 & 2 & 2 \\
Magnesium Stearate & 4 & 4 & 4 & 4 & 4 & 4 & 4 & 4 & 4 \\
Total weight (mg) & 240 & 240 & 240 & 240 & 240 & 240 & 240 & 240 & 240 \\
\hline
\end{tabular}

Table 2. Granule properties of proposed formulations of allopurinol FDTs.

\begin{tabular}{|c|c|c|c|c|c|c|}
\hline \multicolumn{2}{|c|}{ Formulation code } & $\begin{array}{c}\text { Bulk density } \\
(\mathrm{gm} / \mathrm{ml})\end{array}$ & $\begin{array}{c}\text { Tap density } \\
(\mathrm{gm} / \mathrm{ml})\end{array}$ & $\begin{array}{c}\text { Compressibility index } \\
(\%)\end{array}$ & Hausner's ratio & $\begin{array}{c}\text { Angle of } \\
\text { repose }\end{array}$ \\
\hline \multirow[t]{3}{*}{ Group A } & F-1 & 0.513 & 0.719 & 28.651 & 1.402 & $42.34^{\circ}$ \\
\hline & F-2 & 0.493 & 0.702 & 29.772 & 1.424 & $42.60^{\circ}$ \\
\hline & $\mathrm{F}-3$ & 0.499 & 0.712 & 29.916 & 1.427 & $43.67^{\circ}$ \\
\hline \multirow[t]{3}{*}{ Group B } & F-4 & 0.518 & 0.740 & 30.000 & 1.429 & $41.47^{\circ}$ \\
\hline & F-5 & 0.531 & 0.752 & 29.388 & 1.416 & $42.93^{\circ}$ \\
\hline & F-6 & 0.511 & 0.739 & 30.853 & 1.446 & $42.98^{\circ}$ \\
\hline \multirow[t]{3}{*}{ Group C } & F-7 & 0.506 & 0.692 & 26.879 & 1.368 & $43.99^{\circ}$ \\
\hline & F-8 & 0.490 & 0.675 & 27.407 & 1.378 & $44.34^{\circ}$ \\
\hline & F-9 & 0.489 & 0.670 & 27.015 & 1.370 & $44.36^{\circ}$ \\
\hline
\end{tabular}

Table 3. Tablet properties of the different formulations of allopurinol FDTs.

\begin{tabular}{lccccccccc}
\hline Code & F-1 & F-2 & F-3 & F-4 & F-5 & F-6 & F-7 & F-8 & F-9 \\
\hline Thickness* (mm) & $3.15 \pm 0.02$ & $3.19 \pm 0.02$ & $3.15 \pm 0.02$ & $3.11 \pm 0.03$ & $3.17 \pm 0.03$ & $3.15 \pm 0.04$ & $3.18 \pm 0.03$ & $3.13 \pm 0.02$ & $3.14 \pm 0.02$ \\
Diameter* (mm) & $8 \pm 0$ & $8 \pm 0$ & $8 \pm 0$ & $8 \pm 0$ & $8 \pm 0$ & $8 \pm 0$ & $8 \pm 0$ & $8 \pm 0$ & $8 \pm 0$ \\
Weight variation* & $0.26 \pm 0.09$ & $0.35 \pm 0.09$ & $0.37 \pm 0.14$ & $0.37 \pm 0.09$ & $0.45 \pm 0.10$ & $0.43 \pm 0.15$ & $0.39 \pm 0.14$ & $0.51 \pm 0.08$ & $0.41 \pm 0.11$ \\
(\%) & & & & & & & & & \\
Hardness**(Kgf) & $3.20 \pm 0.05$ & $3.11 \pm 0.02$ & $3.01 \pm 0.04$ & $3.04 \pm 0.05$ & $3.15 \pm 0.06$ & $2.97 \pm 0.05$ & $3.04 \pm 0.04$ & $3.19 \pm 0.06$ & $3.10 \pm 0.04$ \\
Friability**(\%) & $0.56 \pm 0.02$ & $0.62 \pm 0.02$ & $0.73 \pm 0.01$ & $0.53 \pm 0.01$ & $0.45 \pm 0.03$ & $0.69 \pm 0.01$ & $0.61 \pm 0.01$ & $0.41 \pm 0.01$ & $0.48 \pm 0.01$ \\
In vitro disinte- & $34.67 \pm 1.20$ & $27.67 \pm 1.45$ & $19.00 \pm 0.58$ & $40.67 \pm 1.20$ & $25.00 \pm 1.53$ & $18.00 \pm 1.00$ & $19.33 \pm 0.67$ & $15.33 \pm 1.45$ & $11.67 \pm 0.88$ \\
gration time**(sec) & & & & & & & & & \\
In vitro dispersion & $61.33 \pm 0.88$ & $54.00 \pm 1.15$ & $48.67 \pm 1.33$ & $65.33 \pm 1.45$ & $60.00 \pm 1.53$ & $50.67 \pm 0.67$ & $53.33 \pm 1.33$ & $44.00 \pm 0.58$ & $32.67 \pm 0.88$ \\
time** (sec) & & & & & & & & & \\
Wetting time** & $45.67 \pm 1.20$ & $36.33 \pm 0.88$ & $28.33 \pm 1.33$ & $50.00 \pm 1.53$ & $45.33 \pm 0.67$ & $34.33 \pm 1.20$ & $37.33 \pm 0.88$ & $27.67 \pm 1.20$ & $21.67 \pm 0.33$ \\
(sec) & & & & & & & & & \\
Water absorption & $99.11 \pm 0.24$ & $105.92 \pm$ & $121.20 \pm$ & $95.78 \pm$ & $101.16 \pm$ & $111.91 \pm$ & $103.05 \pm$ & $116.67 \pm$ & $127.78 \pm$ \\
Ratio** (\%) & & 0.58 & 0.20 & 0.41 & 0.68 & 0.42 & 0.38 & 0.36 & 0.21 \\
Drug content** & $98.65 \pm 0.74$ & $98.97 \pm$ & $100.24 \pm$ & $98.04 \pm$ & $100.89 \pm$ & $99.60 \pm$ & $98.96 \pm$ & $100.25 \pm$ & $100.97 \pm$ \\
(\%) & & 0.75 & 1.10 & 0.80 & 1.13 & 1.32 & 0.46 & 0.48 & 1.16 \\
\hline
\end{tabular}

All values are expressed as Mean \pm SEM; * and ** indicates $n=5$ and $n=3$ respectively. 
Wetting time. ${ }^{18}$ Three trials for each formulation were performed (Table3).

Water absorption ratio. ${ }^{19}$ Water absorption ratio $(\mathrm{R})$ was determined by using the following equation-

$$
\mathrm{R}=\{(\mathrm{Wa}-\mathrm{Wb}) / \mathrm{Wa}\} \times 100
$$

Where, $\mathrm{Wa}=$ weight of tablet after water absorption and $\mathrm{Wb}=$ weight of tablet before water absorption (Table 3).

Drug content. ${ }^{20}$ The percentage of drug content by the following equation for five tablets:

Percent drug content $=$

$$
\frac{\mathrm{A}_{\text {spl }} \times \mathrm{W}_{\text {std }} \times \text { Average Weight } \times \mathrm{P}_{\text {std }}}{\mathrm{A}_{\text {std }} \times \mathrm{W}_{\text {spl }} \times \text { Label Claimed Value }}
$$

Where, $\mathrm{A}_{\mathrm{spl}}=$ absorbance of sample, $\mathrm{W}_{\text {std }}=$ weight of standard, $\mathrm{P}_{\text {std }}=$ potency of standard $(99.003 \%), \mathrm{A}_{\text {std }}=$ absorbance of standard and $\mathrm{W}_{\mathrm{spl}}=$ weight of sample.

In vitro dissolution study. The release rate of allopurinol from fast dissolving tablets was determined using the USP Type II (Rotating paddle method) dissolution test apparatus. It was performed using $900 \mathrm{ml}$ of $0.01 \mathrm{~N} \mathrm{HCl}$ as dissolution medium (according to USP), at $37 \pm 0.5^{\circ} \mathrm{C}$ and $75 \mathrm{rpm}$. A sample solution $(5 \mathrm{ml})$ was withdrawn from the dissolution apparatus at predetermined time intervals of $0.5,2,4,6,8,10,12$ and 15 minutes. The same volume of dissolution medium is replaced to maintain sink condition. Samples withdrawn were filtered through Whatmann filter paper (no.41) and suitably diluted with $0.01 \mathrm{~N} \mathrm{HCl}$. Absorbance of these solutions was measured at $250 \mathrm{~nm}$ using a UV-1800 SHIMADZU UV spectrophotometer. Cumulative percentage of drug release was calculated using an equation obtained from a standard curve. Dissolution rate was studied for all formulations.

\section{RESULTS AND DISCUSSION}

Nine formulations of fast dissolving tablets of allopurinol were prepared with varying concentration of croscarmellose sodium, sodium starch glycolate and crospovidone. For each formulation, blend of drug and excipients were prepared and evaluated for various parameters as explained in table2. The results of loose bulk density and tapped bulk density ranged from 0.489 to 0.531 and 0.670 to 0.752 , respectively. Using above two density data, compressibility index and Hausner's ratio were calculated. Compressibility index of the prepared blends falls in the range of 26.879 to $30.853 \%$ and this is also supported by Hausner's values which were in the range of 1.368 to 1.446.

The mean thickness and diameter was $(\mathrm{n}=5)$ almost uniform in all the formulations and values ranged from $3.11 \pm 0.03$ to $3.19 \pm 0.02 \mathrm{~mm}$ and $8 \pm 0$, respectively. The standard error mean values indicated that all formulations were within the range. Table 3 shows that all the formulated tablets exhibited low weight variation that differed between $0.26 \pm 0.09$ to $0.51 \pm 0.08 \%$ from different batches with acceptable limit as per pharmaceutical specifications. The hardness was found in the range of $2.97 \pm 0.05$ to $3.20 \pm 0.05 \mathrm{kgf}$. The loss in total weight of the tablets due to friability was between $0.41 \pm 0.01$ to $0.73 \pm 0.01 \%$ which was absolutely below $1 \%$ indicating a good mechanical strength with an ability to withstand physical and mechanical stress conditions while handling.

The results of in vitro disintegration were within the specified limit and comply with the criteria for fast dissolving tablets, the value were with $11.67 \pm$ 0.88 to $40.67 \pm 1.20$ seconds. Effect of concentration of superdisintegrants on disintegration time is shown in figure 1. It revealed that disintegration time increased with increase in the concentration of superdisinte grants. The in vitro dispersion time is measured by the time taken to undergo uniform dispersion. Rapid dispersion was observed in the range of $32.67 \pm 0.88$ to $65.33 \pm 1.45$ seconds. Wetting time is closely related to the inner structure of the tablet which showed that wetting process was very rapid ( $21.67 \pm 0.33$ to $50.00 \pm 1.53$ seconds) in almost all formulations. The order of enhancement of the disintegration, dispersion and wetting time with 
various superdisinte grants found to be sodium starch glycolate $>$ croscarmellose sodium $>$ crospovidone.
Water absorption ratio of all formulations ranged from $95.78 \pm 0.41$ to $121.20 \pm 0.20 \mathrm{sec}$.

Table 4. Percent drug release of different batches of allopurinol FDTs.

\begin{tabular}{|c|c|c|c|c|c|c|c|c|c|}
\hline \multirow{3}{*}{$\begin{array}{l}\text { Time } \\
\text { (min) }\end{array}$} & \multicolumn{9}{|c|}{ Percent drug release } \\
\hline & \multicolumn{3}{|c|}{ Group A } & \multicolumn{3}{|c|}{ Group B } & \multicolumn{3}{|c|}{ Group C } \\
\hline & F-1 & F-2 & F-3 & F-4 & F-5 & F-6 & F-7 & F-8 & F-9 \\
\hline 0 & 0 & 0 & 0 & 0 & 0 & 0 & 0 & 0 & 0 \\
\hline 0.5 & 22.07 & 26.14 & 31.39 & 24.21 & 26.68 & 30.54 & 27.96 & 31.5 & 36.75 \\
\hline 2 & 45.44 & 63.79 & 67.25 & 44.17 & 53.61 & 57.71 & 56.41 & 60.6 & 67.38 \\
\hline 4 & 66.16 & 73.46 & 79.3 & 62.74 & 74.37 & 80.53 & 68.93 & 74.01 & 82.86 \\
\hline 6 & 73.49 & 87.69 & 85.84 & 72.3 & 78.53 & 90.29 & 77.35 & 82.56 & 90.5 \\
\hline 8 & 80.75 & 90.31 & 87.71 & 77.73 & 87.43 & 91.43 & 82.38 & 83.98 & 93.78 \\
\hline 10 & 83.01 & 91.88 & 91.51 & 82.55 & 90.8 & 93.22 & 84.33 & 88.51 & 96.01 \\
\hline 12 & 85.29 & 93.34 & 94.04 & 84.61 & 92.37 & 94.79 & 87.36 & 90.06 & 97.6 \\
\hline 15 & 90.25 & 95.67 & 98.08 & 90.21 & 94.37 & 97.24 & 91.05 & 95.69 & 98.88 \\
\hline
\end{tabular}

Table 5. In vitro drug release kinetics for proposed allopurinol FDTs.

\begin{tabular}{ccccccc}
\hline Formulation code & & $\begin{array}{c}\text { Zero order } \\
\text { regression co- } \\
\text { efficient }\left(\mathrm{R}^{2}\right)\end{array}$ & $\begin{array}{c}1^{\text {st }} \text { order } \\
\text { regression co- } \\
\text { efficient }\left(\mathrm{R}^{2}\right)\end{array}$ & $\begin{array}{c}\text { Higuchi } \\
\text { regression co- } \\
\text { efficient }\left(\mathrm{R}^{2}\right)\end{array}$ & $\begin{array}{c}\text { Korsmeyer-Peppas } \\
\text { regression co- } \\
\text { efficient }\left(\mathrm{R}^{2}\right)\end{array}$ & $\begin{array}{c}\text { Hixson-Crowell } \\
\text { regression co- } \\
\text { efficient }\left(\mathrm{R}^{2}\right)\end{array}$ \\
\hline \multirow{3}{*}{ Group A } & F-1 & 0.772 & 0.951 & 0.949 & 0.966 & 0.490 \\
& F-2 & 0.678 & 0.933 & 0.892 & 0.910 & 0.437 \\
& F-3 & 0.661 & 0.956 & 0.881 & 0.915 & 0.413 \\
Group B & F-4 & 0.795 & 0.968 & 0.962 & 0.984 & 0.491 \\
& F-5 & 0.731 & 0.955 & 0.928 & 0.956 & 0.459 \\
Group C & F-6 & 0.676 & 0.939 & 0.893 & 0.936 & 0.431 \\
& F-7 & 0.715 & 0.937 & 0.919 & 0.954 & 0.439 \\
& F-8 & 0.695 & 0.951 & 0.905 & 0.950 & 0.424 \\
\hline
\end{tabular}

Table 6. In vitro drug release mechanism for proposed formulations of allopurinol FDTs using Korsmeyer-Peppas model.

\begin{tabular}{cccc}
\hline \multicolumn{2}{c}{ Formulation code } & Diffusion exponent (n) & Release type \\
\hline Group A & F-1 & 0.416 & Fickian \\
& F-2 & 0.370 & Fickian \\
Group B & F-3 & 0.317 & Fickian \\
& F-4 & 0.392 & Fickian \\
& F-5 & 0.374 & Fickian \\
Group C & F-6 & 0.344 & Fickian \\
& F-7 & 0.339 & Fickian \\
& F-8 & 0.315 & Fickian \\
& F-9 & 0.289 & Fickian \\
\hline
\end{tabular}

Determination of release mechanism from multiple coefficients. The release kinetics parameters of all formulations are presented in table 5 . Based on highest regression co-efficient value $\left(\mathrm{R}^{2}\right)$ the best-fit model for all nine formulations seemed following first-order model. When the data were plotted according to a first-order equation, the formulations F-1, F-2, F-3, F-4, F-5, F-6, F-7, F-8 and F-9 showed a fair linearity, with regression coefficient values of $0.951,0.933,0.956,0.968,0.955$, $0.939,0.937,0.951$ and 0.981 , respectively.

The dissolution data was also fitted to the wellknown exponential equation (Korsmeyer-Peppas 
equation $^{21}$ ), which is often used to describe the drug release mechanism:

$$
\mathrm{M}_{\mathrm{t}} / \mathrm{M}_{\infty}=\mathrm{kt}^{\mathrm{n}}
$$

Where $M_{t} / M_{\infty}$ is fraction of drug released, $k$ is kinetic constant, $\mathrm{t}$ is release time and $\mathrm{n}$ is the diffusional exponent for drug release which gives an indication of the release mechanism. As indicated in table-6, the $\mathrm{n}$ values ranging from 0.289 to 0.416 indicated that the drug release for all the formulations was found to follow Fickian's release. This value $(\mathrm{n} \leq$ 0.45) indicates the diffusion mechanism and suggested that the drug release was controlled by only one process.

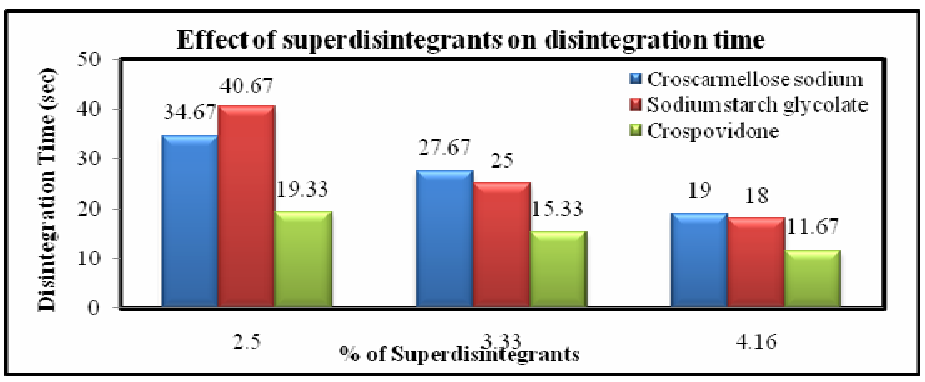

Figure 1. Effect of concentration of superdisintegrants on disintegration time.

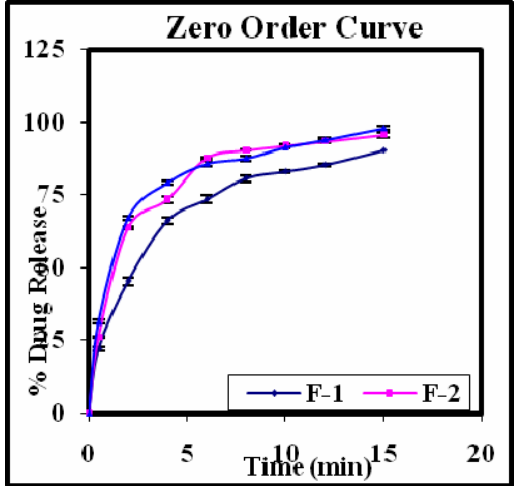

Figure 2. Zero order release model of allopurinol FDTs of group A formulations containing croscarmellose sodium (F-1, F-2 and F-3).

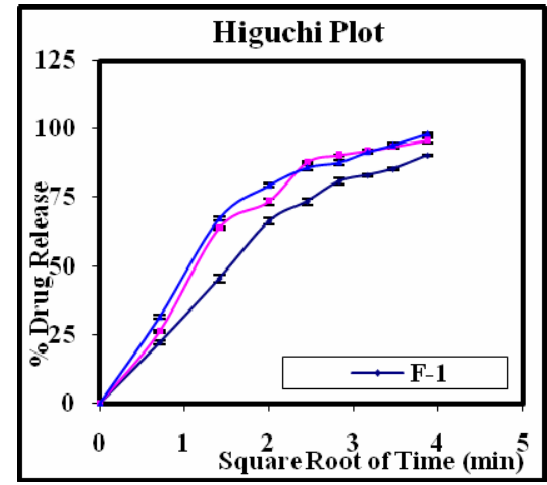

Figure 4.Higuchi release model of allopurinol FDTs of Group A formulations containing croscarmellose sodium (F-1, F-2 and F-3).

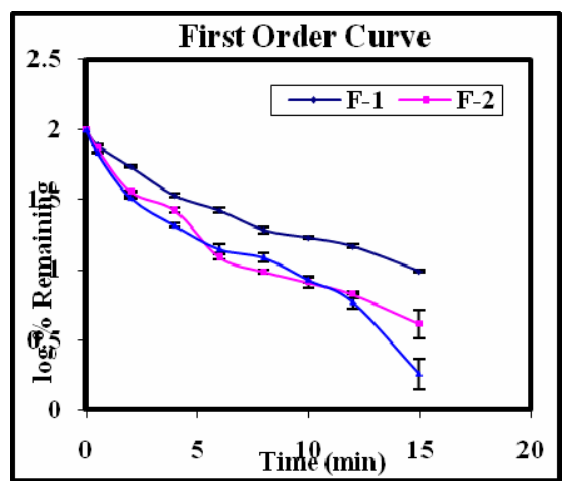

Figure 3. First order release model of allopurinol FDTs of group A formulations containing croscarmellose sodium (F-1, F-2 and F-3).

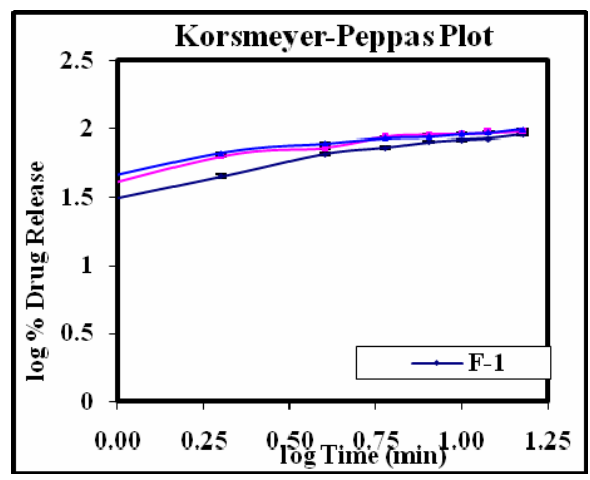

Figure 5.Korsmeyer-Peppas release model of allopurinol FDTs of Group A formulations containing croscarmellose sodium (F-1, F-2 and F-3). 


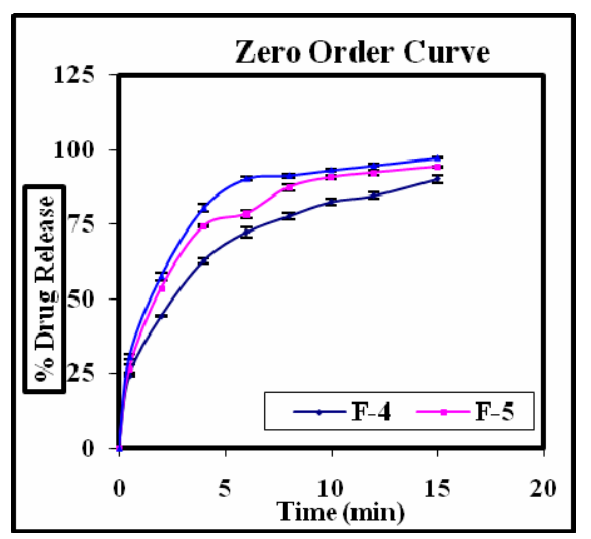

Figure 6. Zero order release model of allopurinol FDTs of Group B formulations containing sodium starch glycolate (F-4, F-5 and F-6).

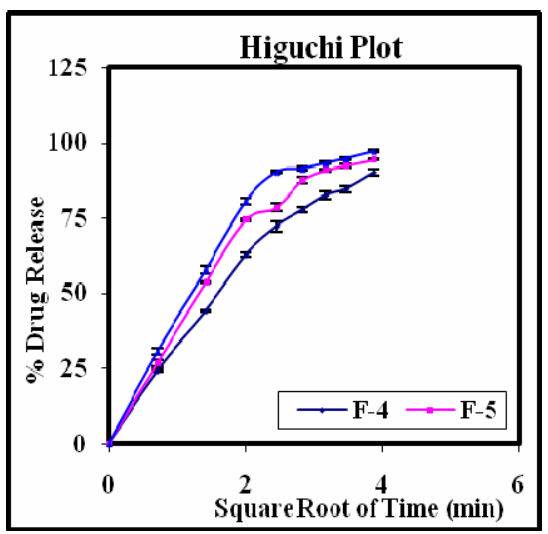

Figure 8. Higuchi release model of allopurinol FDTs of Group B formulations containing sodium starch glycolate (F-4, F-5 and F-6).

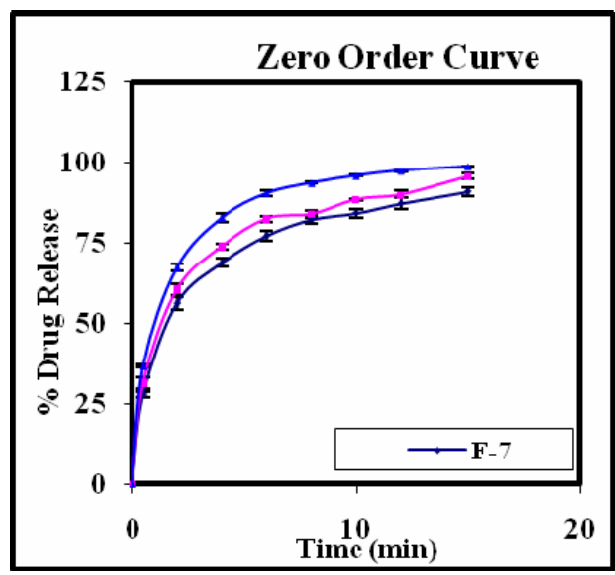

Figure 10. Zero order release model of allopurinol FDTs of Group $\mathrm{C}$ formulations containing crospovidone (F-7, F-8 and F-9).

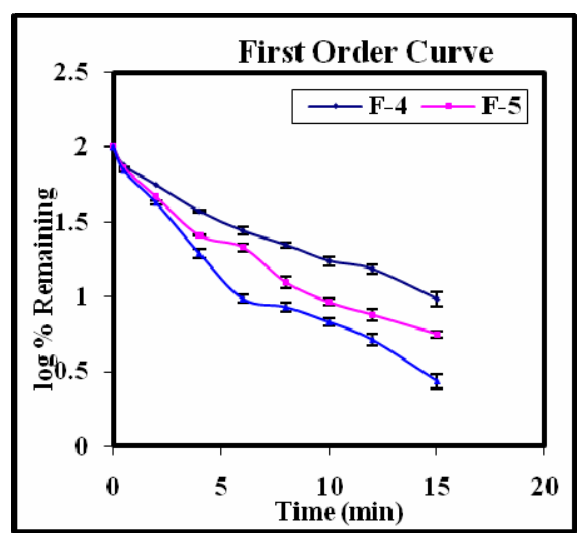

Figure 7. First order release model of allopurinol FDTs of Group B formulations containing sodium starch glycolate (F-4, F-5 and F-6.

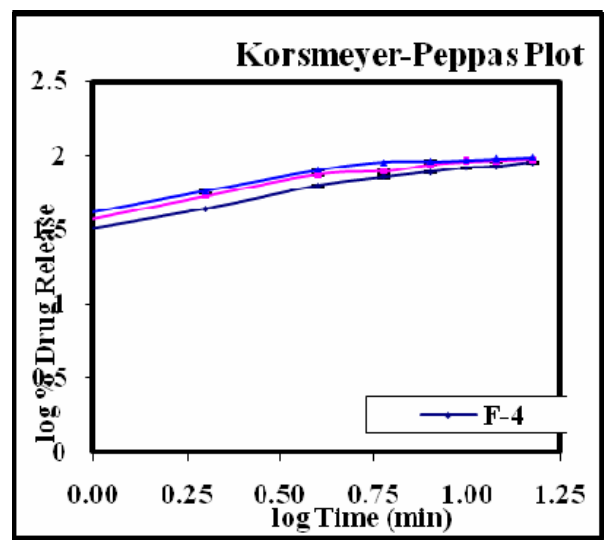

Figure 9. Korsmeyer-Peppas release model of allopurinol FDTs of Group B formulations containing sodium starch glycolate (F-4, F-5 and F-6).

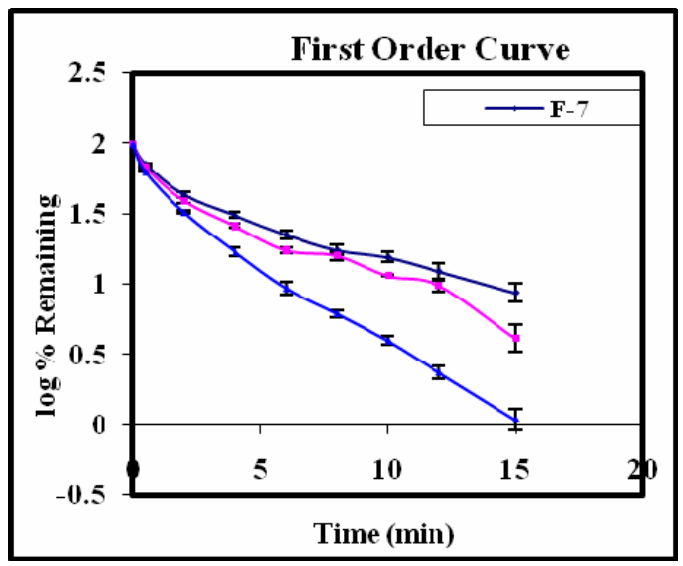

Figure 11. First order release model of allopurinol FDTs of Group C formulations containing crospovidone (F-7, F-8 and F-9). 


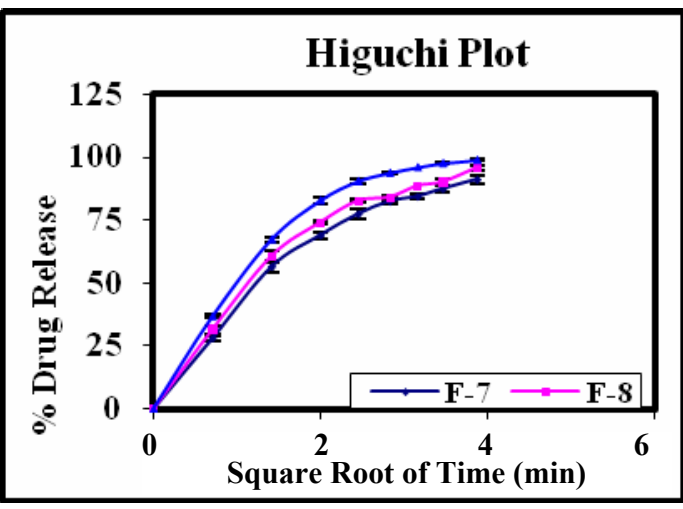

Figure 12. Higuchi release model of allopurinol FDTs of Group C formulations containing crospovidone (F-7, F-8 and F-9).

\section{CONCLUSIONS}

The use of superdisintegrants for preparation of FDTs is highly effective and commercially feasible. These superdisintegrants accelerate disintegration of tablets by their ability to absorb a large amount of water when exposed to an aqueous environment. This disintegration is reported to have an effect on dissolution characteristics as well. According to the studies, the release was found in the following order of superdisintegrants: crospovidone (Group C) > croscarmellose sodium (Group A) > sodium starch glycolate (Group B). In this research work, overall results suggest that FDTs containing Crospovidone $4.17 \%$ (F-9) shows best results in terms of percent drug release, compressibility index, wetting time, in vitro dispersion and in vitro disintegration time. So, the proposed formulation F-9 may be used for the development of allopurinol fast dissolving tablet, for quick onset of action without need of water for swallowing or administration and also to meet the patient's demand for the treatment of gout. However, further investigation is required to establish in vivo in vitro correlation to reveal the accurate pattern of drug release in in vivo environment as well in vivo efficiency of these allopurinol fast dissolving tablets.

\section{ACKNOWLEDGEMENTS}

We acknowledge generous help of Incepta Pharmaceuticals Limited (Savar, Dhaka, Bangladesh) and Globe Pharmaceuticals Limited (Begumgonj,

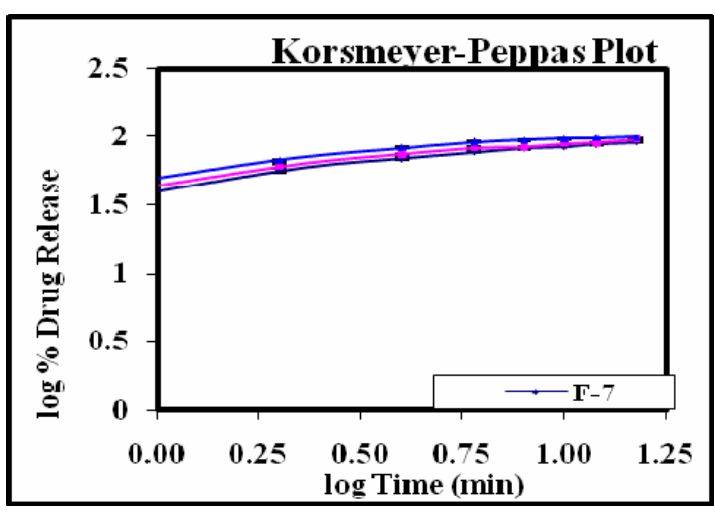

Figure 13. Korsmeyer-Peppas release model of allopurinol FDTs of Group $\mathrm{C}$ formulations containing crospovidone (F-7, F-8 and F-9).

Noakhali, Bangladesh) for providing allopurinol and superdisintegrants respectively.

\section{REFERENCES}

1. Valleri, M., Mura P., Maestrelli, F., Cirri, M. and Ballerini, R. 2004. Development and evaluation of Glyburide fast dissolving tablets using solid dispersion technique. Drug. Dev. Ind. Pharm. 30, 525-534.

2. Sreenivas, S.A., Dandagi, P.M., Gadad, A.P., Godbloe, A.M., Hiremath, S.P. and Mastiholimath, V.S. 2005. Orodispersible tablets: new-fangled drug delivery systems - a Review. Ind. J. Pharm. Edu. Res. 39, 177-181.

3. Berner, B., Birudaraj, R., Shen, S. and Li, X. 2005. Buccal permeation of buspirone: mechanistic studies on transport pathways. J. Pharm. Sci. 94, 70-78.

4. Ishikawa, T., Koizumi, N. and Mukai, B. 2001. Pharmacokinetics of acetaminophen from rapidly disintegrating compressed tablet prepared using microcrystalline cellulose (PH-M-06) and spherical sugar granules. Chem. Pharm. Bull. 49, 230-232.

5. Price, T.M., Blauer, K.L., Hansen, M. and Stanczyk, F. 1997. Single-dose pharmacokinetics of sublingual versus oral administration of micronized 17 beta-estradiol. Obstet. Gynecol. 89, 340-345.

6. Day, R.O., Grham, G.G., Hicks, M., Mclchlan, A.J., Stocker, S.L. and Williams, K.M. 2007. Clinical pharmacokinetics and pharmacodynamics of allopurinol. Clin. Pharmacokinet. 46, 623-644.

7. Samy, A.M., Marzouk M.A., Ammar, A.A. and Ahmed M.K. 2010. Enhancement of the dissolution profile of allopurinol by a solid dispersion technique. Drug. Dis. Ther. 4, 77-84. 
8. Lachman, L., Liberman, A. and Kinig, J.L. 1991. The Theory and Practice of Industrial Pharmacy. Varghese Publishing House, Bombay. $2^{\text {nd }}$ ed. pp. 67-68.

9. Longer, M.A. and Robinson, J.R. 1990. Remington's Pharmaceutical Sciences. Mack Publishing Company, Pennsylvania. $18^{\text {th }}$ ed. pp. $1675-1684$.

10. Carr, R.L. 1965. Evaluating flow properties of solids. Chem. Eng. 72, 163-168.

11. Lindberg, N., Palsson, M., Pihl, A., Freeman, R., Freeman, T., Zetzener, H., and Enstad, G. 2004. Flowability measurements of pharmaceutical powder mixtures with poor flow using five different techniques. Drug. Dev. Ind. Pharm. 30, 785-791.

12. Carter, S.J. 1986. Cooper and Gunn's Tutorial Pharmacy. CBS Publishers and Distributors, Delhi. $6^{\text {th }}$ ed., pp. 225.

13. Gupta, A.K. 1994. Introduction to Pharmaceutics-I. CBS publishers, Delhi, $3^{\text {rd }}$ ed. pp. 267-268.

14. British Pharmacopoeia. 2000. Her Majesty's stationary office, London, England. 2, pp. 266-268.

15. Abdelbary, G., Eouani, C., Prinderre, P., Joachim, J., Reynier, J.P. and Piccerelle, P.H. 2004. Determination of the in vitro disintegration profile of rapidly disintegrating tablets and correlation with oral disintegration. Int. J. Pharm. 292, $29-41$.
16. Sweetman, S.C. 2002. Martindale: The Complete Drug Reference. Pharmaceutical Press, London. $33^{\text {rd }}$ ed. pp. 12351237.

17. Battue, S.K., Repay, M.A., Maunder, S. and Rio, M.Y. 2007. Formulation and evaluation of rapidly disintegrating tablet Fenoverine Tablets: effect of superdisintegrants. Drug. Dev. Ind. Pharm. 33, 1225-1232.

18. Bi, Y., Sunada, H., Yonezawa, Y., Danjo, K., Otsuka, A. and Iida, K. 1996. Preparation and evaluation of a compressed tablet rapidly disintegrating in the oral cavity. Chem. Pharm. Bull. 44, 2121-2127.

19. Vijaya, K.S.G. and Mishra, D.N. 2006. Rapidly disintegrating oral tablets of Meloxicam. Indian Drugs 43, 117-121.

20. Korsmeyer, R.W., Gurny, R., Doelker, E.M., Buri, P. and Peppas N.A. 1983. Mechanism of solute release from porous hydrophilic polymers. Int. J. Pharm. 15, 25-35. 